\section{Mandarin Attributes Preferred by Consumers in Grocery Stores}

\author{
Benjamin L. Campbell, ${ }^{2}$ Robert G. Nelson, ${ }^{1}$ Robert C. Ebel ${ }^{2}$, and \\ William A. Dozier ${ }^{2}$ \\ Alabama Agricultural Experiment Station, Auburn University, AL 36849
}

Additional index words. conjoint analysis, segmentation, simulation, Citrus unshiu

Abstract. For most grocery stores, external quality standards require that premium mandarins be orange, unblemished, and large. Thus, for consumers to differentiate among the premium mandarins on any dimension other than price, additional positioning attributes must be evaluated. This study considered consumer preferences for price $(\$ 2.18 / \mathbf{k g}, \$ 4.39$ / $\mathrm{kg}$, or $\$ 15.41 / \mathrm{kg})$, packaging $(1.36 \mathrm{~kg}$ of loose fruit, $1.36-\mathrm{kg}$ bag, $2.27-\mathrm{kg}$ box, or $0.23-\mathrm{kg}$ clamshell with peeled fruit sections), type of mandarin (clementine, satsuma, tangerine), shelf life from the day of purchase $(3,14$, or 31 days), and vitamin $C$ content (with or without a label stating high in vitamin C). A conjoint survey was conducted in four grocery stores located in Birmingham and Montgomery, Ala. In total, 289 respondents used a 7-point intention-to-buy scale to rate photographs of 16 product profiles. Six market segments were identified, based on maximal similarity of preferences within each segment and maximal differences between segments. A simulation was conducted of the effect that an introduction of peeled-and-sectioned satsumas would have on the market share and gross revenue of other mandarins. This product showed great potential, but should be offered in a product mix that includes the loose form as well. Labeling for vitamin $\mathrm{C}$ was preferred by all segments, but did not contribute much to the intention-to-buy rating. Awareness and recognition of satsumas needs to be addressed in promotional campaigns. The longest shelf life was the first choice of almost half the respondents.

Most grocery stores have stringent quality requirements for citrus fruits, especially regarding external appearance. In order to be acceptable to consumers, mandarins such as tangerines, clementines and satsumas, should be orange with no green patches, unblemished, and large (Campbell et al., 2004).

Since most grocery stores require their mandarins to be of this standard external quality, other features and benefits must be considered as attributes that consumers might value in differentiating between mandarin products. Among the candidates for these alternative, secondary attributes are packaging, type of mandarin, shelf life and vitamin $\mathrm{C}$ content. A primary objective of the current study was to evaluate consumer preferences for those four attributes, as well as price. Quantifying the value of these attributes will allow mandarin growers to assess the tradeoffs between the costs and benefits of various attributes, identify features that should be highlighted in promotional efforts, and mitigate any perceived weaknesses. For example, it is obviously more costly to provide consumers with a peeled-

Received for publication 25 Jan. 2006. Accepted for publication 7 Mar. 2006. This project was funded in part by the Alabama Department of Agriculture and Industries, a grant from the USDA FederalState Marketing Improvement Program, and the AlabamaAgricultural Experiment Station. We thank Deacue Fields and Floyd Woods for reviewing the manuscript, and Bruno's Supermarkets, Inc. for their cooperation in conducting the survey.

${ }^{1}$ Department of Agricultural Economics and Rural Sociology, 202 Comer Hall, Auburn University, AL 36849. Corresponding author; e-mail rnelson@acesag.auburn.edu.

${ }^{2}$ Department of Horticulture, 101 Funchess Hall, Auburn University, AL 36849. and-sectioned product, but if they are willing to pay a substantially higher price for the benefit of convenience, then it may be a profitable alternative form to consider. As another example, there may be certain consumers who value the information about the high vitamin $\mathrm{C}$ content in mandarins, and who could be targeted in specialized promotional efforts to increase their consumption of mandarins. Finally, a significant weakness for certain mandarins - particularly satsumas - may be that consumers are unfamiliar with their name, suggesting that one way to mitigate the problem would be for initial promotional efforts to be directed toward raising awareness and recognition of that type of mandarin.

Asecond important objective of the current study was to combine consumers with similar preferences into groups or segments. One way to do this is to group consumers into segments so that their preference profiles are as similar as possible within a segment, but are as different as possible between one segment and another. More attractive segments can then be targeted for marketing campaigns.

A final objective was to explore the market potential for a new mandarin product made from peeled-and-sectioned fruit. Apart from the convenience to the consumer of a ready-toeat form, this product would benefit producers since it can be made from fruit that would otherwise be culled because of minor defects in external appearance. Although this product of the survey, respondents had no difficulty expressing preferences for the prototype.

\section{Materials and Methods}

Conjoint analysis has long been a leading was not available in the study region at the time technique for analyzing consumer tradeoffs (Green et al., 2001). Conjoint analysis begins by asking consumers to evaluate products with varying attributes and levels (where, for example, price is an attribute and $\$ 2.18 / \mathrm{kg}$ is a level). By allowing a respondent to evaluate enough combinations of attributes with varying levels, an estimate of value can be obtained for each attribute and level. Numerous horticultural products have been subjected to conjoint analysis, including peanuts (Nelson et al., 2005), Christmas trees (Behe et al., 2005), satsumas (Campbell et al., 2004), edibleflowers (Kelley et al., 2002), bell peppers (Frank et al., 2001), and geraniums (Behe et al., 1999).

Communication with food distributors and citrus fruit experts, along with the published literature, was used to identify mandarin attributes that are most important to consumers. The attributes and levels that were described or illustrated in photographic representations presented to the survey participants included price $(\$ 2.18 / \mathrm{kg}, \$ 4.39 / \mathrm{kg}$, or $\$ 15.41 / \mathrm{kg})$, packaging (1.36-kg bag, 2.27-kg box, 1.36-kg of loose whole fruit, or $0.23 \mathrm{~kg}$ of peeled-andsectioned fruit), type of mandarin (clementine, satsuma, or tangerine), shelf life from the day of purchase $(3,14$, or $31 \mathrm{~d})$, and vitamin C content (with or without a label stating "high in vitamin C").

Attributes. The $\$ 2.18 / \mathrm{kg}$ and $\$ 4.39 / \mathrm{kg}$ price levels represented the lowest and highest prices for premium, whole mandarins found in grocery stores in the study region. The $\$ 15.41 / \mathrm{kg}$ price represented the upper end of prices for further-processed, value-added products such as preprepared melons, pineapple, berries, and other fresh-cut fruit.

In addition to the conventional forms for presenting citrus (loose, bag, and box), a value-added product form was included. This hypothetical convenience form consisted of $0.23 \mathrm{~kg}$ of peeled mandarin sections enclosed in a clear plastic clamshell container.

Product name recognition can also be an important promotional consideration. In order to evaluate preferences for mandarin product category, the three "levels" were simply the names of the fruits: satsuma, clementine, and tangerine.

Shelf life, or the amount of time a fruit maintains its quality after purchase by the consumer, may be an important attribute amenable to improvement or differentiation. A number of postharvest technologies have been developed to increase shelf life in citrus. With normal handling, mandarin shelf life is usually between 14 and 28 d postpurchase, so the three levels of shelf life chosen were: extremely short ( $3 \mathrm{~d})$, midrange (14 d), and extended (31 d).

There is currently a popular perception that fruits confer significant health benefits, including those associated with vitamin $\mathrm{C}$. Thus, to capture the effect of preferences for vitamin C, the pictorial representations were either labeled high in vitamin $\mathrm{C}$ or had no label.

Stimuli. By using a fractional-factorial design, respondents only had to evaluate 16 of the 216 possible stimuli in order to capture the main effects of the treatments. Photographs 
$(21.6 \mathrm{~cm}$ by $33.7 \mathrm{~cm})$ and text were used as the stimuli. The photographs illustrating the $1.36-\mathrm{kg}$ bag showed 15 fruit in a thin-mesh red net bag. Those for the $2.27-\mathrm{kg}$ box showed 15 fruit on the top layer of a plain wooden citrus fruit box with a red net cover (similar to those used in grocery stores, but with all labeling removed from the box). The loose fruit were arranged in a pyramid of 14 fruit weighing $1.36 \mathrm{~kg}$.

Since we were evaluating consumers' perceptions associated with the names of the various mandarins, rather than any differences in appearance or phenotype, we used clementines as the generic, or archetypal mandarin in all the photographs. This was necessary to control for variation in individual fruit appearance and, judging by the lack of comments, was noticed by few respondents. The text above the picture indicated the name of the mandarin, package type, price per pound, and total price, while the text below denoted days of shelf life, and either the statement "high in vitamin C" or a blank space.

Two major cities in Alabama-Birmingham and Montgomery — were selected for the study because they had been proposed as regions for possible expansion of satsuma marketing efforts. In each city, four grocery stores, representing a wide range of demographic and socioeconomic characteristics, were selected as survey sites. Shoppers in these stores were asked to participate in the survey and, if willing, were given verbal instructions on how to fill out the survey and informed consent forms. Participants were asked to examine each picture and place a rating mark on a 7point willingness-to-purchase scale, with $1=$ definitely would NOT purchase, 7 = definitely

Table 1. Preference coefficients, relative importance, adjusted $\mathbf{R}^{2}$ and demographics for segments and total sample.

\begin{tabular}{|c|c|c|c|c|c|c|c|}
\hline $\begin{array}{l}\text { Attributes } \\
\text { and levels }\end{array}$ & $\begin{array}{l}\text { "Shelf-life" } \\
\text { Segment }\end{array}$ & $\begin{array}{c}\text { "Convenience" } \\
\text { Segment }\end{array}$ & $\begin{array}{l}\text { "No-handling" } \\
\text { Segment }\end{array}$ & $\begin{array}{c}\text { "Price- } \\
\text { sensitive" } \\
\text { Segment }\end{array}$ & $\begin{array}{l}\text { "Loose-fruit" } \\
\text { Segment }\end{array}$ & $\begin{array}{c}\text { "Fuzzy" } \\
\text { preferences" } \\
\text { Segment }\end{array}$ & $\begin{array}{c}\text { Total } \\
\text { sample }\end{array}$ \\
\hline Number of observations & 61 & 50 & 26 & 40 & 41 & 71 & 289 \\
\hline Market share (\%) & 21.1 & 17.3 & 9.0 & 13.8 & 14.2 & 24.6 & 100.0 \\
\hline Intercept (base rating) & $3.70^{*}$ & 3.78 & 4.20 & 3.86 & $3.34^{*}$ & $4.51^{*}$ & 3.93 \\
\hline \multicolumn{8}{|l|}{ Price/kg } \\
\hline S $2.18 / \mathrm{kg}$ & 0.73 & 0.81 & $0.27^{*}$ & $1.76^{\circ}$ & 0.52 & $0.23^{*}$ & 0.70 \\
\hline$\$ 4.39 / \mathrm{kg}$ & $.53^{*}$ & 0.10 & $-0.07^{\bullet}$ & 0.29 & 0.06 & $-0.02^{\circ}$ & 0.17 \\
\hline$\$ 15.41 / \mathrm{kg}$ & $-1.26^{*}$ & -0.91 & $-0.19^{*}$ & $-2.00^{\circ}$ & $-0.58^{\circ}$ & $-0.21^{*}$ & -0.86 \\
\hline Relative importance (\%) & 24.9 & 22.7 & $12.0^{*}$ & $46.0^{*}$ & $19.8^{*}$ & $17.6^{*}$ & 23.8 \\
\hline \multicolumn{8}{|l|}{ Package type } \\
\hline Bag & -0.51 & $-0.83^{*}$ & $0.99 *$ & -0.3 & 0.07 & 0.00 & -0.14 \\
\hline Box & -0.82 & $-1.39^{*}$ & $0.64^{*}$ & $-0.68^{\circ}$ & -0.66 & $0.02^{*}$ & -0.44 \\
\hline Loose & $0.46^{*}$ & 0.67 & $1.03^{*}$ & 0.41 & $1.62^{\circ}$ & $-0.07^{*}$ & 0.54 \\
\hline Peeled-and-sectioned & 0.87 & $1.55^{\circ}$ & $-2.67^{\bullet}$ & $0.58^{\circ}$ & $-1.03^{\bullet}$ & 0.06 & 0.04 \\
\hline Relative importance $(\%)$ & $18.8^{\circ}$ & $42.0^{*}$ & $57.9^{*}$ & $22.2^{*}$ & $39.9^{\circ}$ & $26.8^{\circ}$ & 31.8 \\
\hline \multicolumn{8}{|l|}{ Mandarin type } \\
\hline Satsuma & -0.28 & -0.13 & $0.01^{*}$ & -0.19 & -0.21 & -0.24 & -0.20 \\
\hline Clementine & $0.49 *$ & $-0.21^{*}$ & 0.17 & -0.09 & 0.12 & -0.05 & 0.07 \\
\hline Tangerine & $-0.21^{*}$ & $0.34^{*}$ & $-0.18^{*}$ & 0.28 & 0.10 & $0.29^{*}$ & 0.12 \\
\hline Relative importance (\%) & 13.7 & 14.0 & $10.8^{*}$ & 12.8 & 14.3 & $24.6^{*}$ & 16.1 \\
\hline \multicolumn{8}{|l|}{ Shelf-life } \\
\hline 3 days & $-1.63^{*}$ & -0.41 & $-0.11^{*}$ & $-0.04^{*}$ & $-0.11^{*}$ & $-0.26^{*}$ & -0.51 \\
\hline 14 days & $0.37^{*}$ & 0.23 & -0.04 & 0.00 & $-0.09^{*}$ & 0.15 & 0.14 \\
\hline 31 days & $1.26^{*}$ & $0.18^{*}$ & 0.15 & $0.04^{*}$ & 0.21 & $0.11^{*}$ & 0.38 \\
\hline Relative importance (\%) & 35.9 & $15.6^{*}$ & $13.6^{*}$ & $12.7^{*}$ & $15.7^{*}$ & 21.7 & 20.8 \\
\hline \multicolumn{8}{|l|}{ Vitamin $\mathrm{C}$ label } \\
\hline Label & 0.15 & 0.11 & 0.05 & 0.10 & $0.27^{*}$ & 0.16 & 0.15 \\
\hline No label & -0.15 & -0.11 & -0.05 & -0.10 & $-0.27^{\bullet}$ & -0.16 & -0.15 \\
\hline Relative importance (\%) & 6.6 & $5.7^{\bullet}$ & 5.6 & 6.3 & $10.3^{*}$ & $9.4^{\circ}$ & 7.5 \\
\hline Adjusted $\mathrm{R}^{2}$ & 0.55 & $0.66^{*}$ & $0.75^{\circ}$ & 0.61 & 0.53 & $0.40^{*}$ & 0.55 \\
\hline \multicolumn{8}{|l|}{ Survey location } \\
\hline Store 4 & 7 & 10 & 4 & 10 & 12 & 13 & 10 \\
\hline Store 1 & 15 & 20 & 19 & 10 & 10 & 11 & 14 \\
\hline Store 3 & 25 & 30 & 35 & 18 & 15 & 17 & 22 \\
\hline Store 2 & 33 & 28 & 19 & 18 & 32 & 32 & 28 \\
\hline Store 6 & 13 & 8 & 4 & $25^{*}$ & 7 & 10 & 11 \\
\hline Store 5 & 3 & 4 & 8 & 10 & 10 & 6 & 6 \\
\hline Store 7 & 5 & $2^{*}$ & 12 & 10 & 15 & 11 & 9 \\
\hline Allergic to sweet citrus ( $\%$ yes) & 8 & 6 & $15^{*}$ & 5 & 2 & 4 & 6 \\
\hline Sweet citrus purchases $(\mathrm{kg} / \mathrm{mo}$.) & 2.98 & 2.54 & 3.40 & 3.32 & 2.46 & 3.85 & 3.13 \\
\hline Buy citrus at grocery store ( $\%$ yes) & 79 & $94^{*}$ & $61^{*}$ & 88 & 73 & 86 & 82 \\
\hline Purchase for Christmas? (\% yes) & $54^{*}$ & 34 & 46 & 50 & 34 & 32 & 41 \\
\hline Age (years) & 43.89 & 44.38 & $39.65^{*}$ & $52.00^{*}$ & 48.46 & 45.96 & 45.87 \\
\hline Gender ( $\%$ female) & 77 & 80 & 77 & 78 & 81 & 66 & 76 \\
\hline Ethnicity ( $\%$ Caucasian) & $89^{*}$ & 78 & 65 & 75 & 63 & 63 & 73 \\
\hline Education (years) & 14.42 & 14.76 & 14.38 & 13.93 & 14.18 & 13.69 & 14.20 \\
\hline Income category (5-535K-50K) & 5.90 & 5.96 & 5.32 & 5.40 & 5.32 & 5.37 & 5.57 \\
\hline Mean income & $\$ 48,427$ & $\$ 49,327$ & $\$ 39,800$ & $\$ 41,000$ & $\$ 39,800$ & $\$ 40,507$ & $\$ 43,549$ \\
\hline \multicolumn{8}{|l|}{ Household structure } \\
\hline Houschold with child $<9$ years & 23 & 28 & 35 & 23 & 12 & 23 & 23 \\
\hline Houschold with child 9-18 years & 38 & 32 & 50 & 25 & 39 & 38 & 36 \\
\hline Single-person household & 25 & 26 & 15 & 23 & 24 & 24 & 23 \\
\hline Heard of satsumas ( $\%$ yes) & 39 & 44 & 42 & 50 & 49 & 37 & 42 \\
\hline Tasted satsumas ( $\%$ yes) & 30 & 30 & 19 & 43 & 42 & 28 & 32 \\
\hline
\end{tabular}

- Significantly different $(\mathrm{p}<0.10)$ from overall sample in a two-tail $t$ test. 
would purchase, $4=$ may or may not purchase, and $2,3,5$, and $6=$ untitled, intermediate response levels. Respondents were advised that they could place their mark anywhere on the scale, including any space between the integers (such marks were later interpolated to the nearest tenth of a rating point). Order bias was minimized by rearranging the order of the photographs from one store to the next, and by allowing consumers to start the survey on any photograph.

When respondents finished evaluating the 16 photographs, they were asked to answer a number of demographic and usage questions. The demographic questions included year of birth, gender, ethnic group, years of education, household age structure, and income category. The usage questions consisted of sweet citrus purchase frequency (times permonth), quantity of sweet citrus purchased each time, purchase occasions (e.g., Christmas), awareness of satsumas (yes or no), previous consumption of satsumas (yes or no), and sweet citrus allergies (yes or no).

Data analysis. Respondents provided a total of 289 usable surveys. Ordinary least squares regression was used to estimate a preference model for each respondent. The model was specified as follows:

$\mathrm{R}_{\mathrm{i}}=\mathrm{B}_{1}+\mathrm{B}_{2}(\mathrm{Pr} 2)+\mathrm{B}_{3}(\mathrm{Pr} 3)+\mathrm{B}_{4}(\mathrm{Pk} 2)+\mathrm{B}_{5}(\mathrm{Pk} 3)$ $+\mathrm{B}_{6}(\mathrm{Pk} 4)+\mathrm{B}_{7}(\mathrm{~T} 2)+\mathrm{B}_{8}(\mathrm{~T} 3)+\mathrm{B}_{9}(\mathrm{~S} 2)+\mathrm{B}_{10}(\mathrm{~S} 3)$ $+\mathrm{B}_{11}(\mathrm{~L} 2)+\mathrm{e}_{\mathrm{i}}$,

where, $\mathrm{R}_{\mathrm{i}}$ denotes the rating of the stimulus given by respondent $i$ on the 7-point scale; $\operatorname{Pr} 2=\$ 4.39 / \mathrm{kg}$ price level; $\operatorname{Pr} 3=\$ 15.41 / \mathrm{kg}$ price level; $\mathrm{Pk} 2=1.36-\mathrm{kg}$ bag; $\mathrm{Pk} 3=2.27-\mathrm{kg}$ box; $\mathrm{Pk} 4$ = peeled-and-sectioned form; $\mathrm{T} 2=$ clementine fruit type; $\mathrm{T} 3=$ tangerine fruit type; S2 = 14-d shelf life; S3 = 31-d shelf life; and $\mathrm{L} 2=$ no vitamin $\mathrm{C}$ label. The independent variables were effects coded, which transforms the coefficients into deviations from the mean to simplify interpretation (Hair et al., 1998).

The relative importance of each attribute was calculated according to Hair et al. (1998):

$R_{i}=\left(\right.$ range $_{i} / \sum_{i=1}^{5}$ range $\left._{i}\right) * 100$

where $\mathrm{RI}_{\mathrm{i}}$ is the relative importance of attribute $i$, and range is the range of the respondent's coefficients for attribute $i$. Relative importance values are interpreted as the percentage of a consumer's buying decision that is contributed by that attribute, and make it possible to compare the importance of various attributes.

Using cluster analysis, respondents with similar coefficients (preferences) were grouped together to identify possible market segments (Green and Helsen, 1989). Since specifying the number of segments within a market is largely a matter of practical considerations, several clustering algorithms were evaluated, including Ward, McQuitty, Equal Variance Maximum Likelihood, Flexible Beta, and Complete Linkage (SAS, 1987). Among these methods, the most frequently-indicated number of clusters was six. The SAS procedures described in Campbell et al. (2004) were then used to assign each respondent to one of the six clusters, again using only their preference coefficients as variables.

After each respondent was assigned membership in a segment based on their preferences for the various levels of attributes, a multinomial logit model was constructed to determine the relationship between segment membership and the demographic and usage variables collected in the survey. Since the purpose of this study was to consider even the most tenuous of the latent relationships between respondent characteristics and product preferences, coefficients from the multinomial logit model with $p$ values as high as 0.30 were interpreted as potentially significant.

\section{Results and Discussion}

Results for the total sample (i.e., before clustering) are shown in the rightmost column of Table 1. There are four major types of statistics in this table: preference coefficients, relative importance, adjusted $R^{2}$, and demographics. These statistics were calculated for each respondent, but only the sample and segment averages are reported.

Preference coefficients are the weights that the average consumer places on that attribute's level in expressing their intention to buy-in short, their preference for that level.

Relative importance is a summary measure of the proportion of influence that the attribute contributes to the buying decision.

Adjusted $R^{2}$ is a measure of how well the model explains respondents' ratings.

Demographics are averages of the responses given in the second part of the survey.

Package type had the largest impact on the total sample's intention-to-buy, making up $31.8 \%$ of the buying decision. Price $(23.8 \%)$, shelf life $(20.8 \%)$, and type of mandarin $(16.1 \%)$ were also important, while vitamin C label (7.5\%) had only a small influence on average intention-to-buy.

Cluster analysis revealed six segments that might yield actionable marketing information. Based on the average coefficients and relative importance values of each segment, these six segments were named as follows: shelf life, convenience, no handling, price sensitive, loose fruit, and fuzzy preferences. Our reasons for giving these segments their fanciful names are explained in the following paragraphs.

The shelf-life segment represented $21 \%$ of the sample, and was characterized by the large relative importance it placed on shelf life ( $36 \%$ of the intention to buy), and its strong preference for the extended (31-d) shelf life,

Table 2. Percentage of respondents choosing a specified level as their first choice, by segment.

\begin{tabular}{|c|c|c|c|c|c|c|c|}
\hline $\begin{array}{l}\text { Attributes } \\
\text { and levels }\end{array}$ & $\begin{array}{l}\text { "Shelf-life" } \\
\text { Segment }\end{array}$ & $\begin{array}{c}\text { "Convenience" } \\
\text { Segment }\end{array}$ & $\begin{array}{c}\text { "No-handling" } \\
\text { Segment }\end{array}$ & $\begin{array}{l}\text { "Price- } \\
\text { sensitive" } \\
\text { Segment }\end{array}$ & $\begin{array}{c}\text { "Loose-fruit" } \\
\text { Segment }\end{array}$ & $\begin{array}{c}\text { "Fuzzy- } \\
\text { preferences" } \\
\text { Segment }\end{array}$ & $\begin{array}{r}\text { Total } \\
\text { sample }\end{array}$ \\
\hline \multicolumn{8}{|l|}{ Price/kg } \\
\hline S $2.18 / \mathrm{kg}$ & 61 & 74 & 65 & $98^{*}$ & 71 & $51^{*}$ & 67 \\
\hline$\$ 4.39 / \mathrm{kg}$ & $38^{*}$ & 20 & 15 & $3^{*}$ & 24 & 32 & 25 \\
\hline$\$ 15.41 / \mathrm{kg}$ & $2^{*}$ & 6 & $19^{*}$ & $0^{*}$ & 5 & $17^{*}$ & 8 \\
\hline \multicolumn{8}{|l|}{ Package type } \\
\hline Bag & 7 & $0^{*}$ & $42^{*}$ & 10 & 5 & $27^{*}$ & 14 \\
\hline Box & 10 & $0^{*}$ & 12 & 3 & 0 & $20^{*}$ & 8 \\
\hline Loose & 39 & $26^{*}$ & 46 & 43 & $95^{*}$ & $24^{*}$ & 42 \\
\hline Peeled-and-sectioned & 46 & $74^{*}$ & $0^{*}$ & 45 & $0^{*}$ & 30 & 36 \\
\hline \multicolumn{8}{|l|}{ Mandarin type } \\
\hline Satsuma & 13 & 22 & 23 & 20 & 10 & 24 & 19 \\
\hline Clementine & $66^{*}$ & $12^{*}$ & 46 & 30 & 41 & $24^{*}$ & 36 \\
\hline Tangerine & $21^{*}$ & $66^{*}$ & 31 & 50 & 49 & 52 & 45 \\
\hline \multicolumn{8}{|l|}{ Shelf-life } \\
\hline 3 days & $0^{*}$ & 22 & 35 & 33 & 32 & 21 & 21 \\
\hline 14 days & 23 & $44^{\circ}$ & 27 & 20 & 22 & 37 & 30 \\
\hline 31 days & $77^{*}$ & $34^{\circ}$ & 38 & 48 & 46 & 42 & 49 \\
\hline \multicolumn{8}{|l|}{ Vitamin $\mathrm{C}$ label } \\
\hline Label & 69 & 54 & 69 & 58 & 76 & 66 & 65 \\
\hline No label & 31 & 46 & 31 & 43 & 24 & 34 & 35 \\
\hline
\end{tabular}

* Significantly different $(\mathrm{p}<0.10)$ from overall sample in a two-tail $t$ test. 
as evidenced by an average coefficient of 1.26 , which was more than three times larger than that of the total sample. Conversely, respondents in this segment strongly disfavored fruit with a shelf life of only three days. Table 2 shows that a large majority of respondents $(77 \%)$ revealed the 31-d level as their first choice, while not one preferred the 3-d level. In principle, this table is constructed by figuratively posing this question to each respondent's model: "Among the levels within an attribute, if this respondent had to choose the one level that is most-preferred (i.e., their first choice), what would that level be, holding all other attribute levels constant?" In practice, the first choice is represented by the coefficient with the largest positive value, among the levels within an attribute, in that respondent's model. The percentage distribution of these first-choices from all 289 respondents is shown in the rightmost column in Table 2, and preceded by the distributions for each segment in the first six columns.

The attribute of second greatest importance to this segment was price, with the highest price more strongly disfavored by this segment than most other segments. The lowest price $(\$ 2.18 / \mathrm{kg})$ was, as expected, the most favored. However, the middle price $(\$ 4.39 / \mathrm{kg})$ was also surprisingly well-accepted, being chosen by $38 \%$ of the respondents in this segment as their most preferred level in Table 2 . This suggests that these consumers may consider price to be an indicator of quality in this situation, and the lower price may have been interpreted as evidence that those fruit were of lower quality.

The lower half of Table 1 shows the average demographics for each segment and compares them to the total sample using a two-tail $t$ test.
The shelf-life segment was significantly more likely than the total sample to purchase fruit for the Christmas season ( $54 \%$ vs. $41 \%$ ), and represented a higher percentage of Caucasians than non-Caucasians ( $89 \%$ vs. $73 \%$ ). This was corroborated by the marginal probabilities in Table 3, which quantify the demographic and usage factors that influence the probability of membership in a segment. Table 3 reports the coefficients that represent the percentage change in the probability of being in a particular segment (which is identified at the top of the columns), given a one-unit change in the average of the independent variable (which is identified at the left of the rows) if the variable is continuous, or given a change from no to yes if the variable is discrete (Liao, 1994, p. 47). The $p$ values associated with each coefficient are in the adjacent column. For the shelf-life segment, only three demographic variables were considered significant (i.e., $p \leq 0.30)$ : purchase for Christmas season $(p$ $=0.14)$, age $(p=0.00)$, and ethnicity $(p=$ 0.12 ). The coefficients on these effects were interpreted as follows: if the answer was yes as to whether a respondent purchases sweet citrus for Christmas, then the probability of that respondent being in the shelf-life segment increased by about $12 \%(0.1223)$; if there was an increase of one year in the average age of the total sample (i.e., from 45.87 years to 46.87 years), then the probability of the average respondent being in this segment decreased by $0.43 \%$; if a respondent was Caucasian then his or her probability of being in this segment increased by $25 \%$.

While the cluster procedure assigned respondents to a particular segment based on the similarity of their preferences for attribute levels, the multinomial logit (MNL) model was constrained by our assumption that the marketing manager would not have access to such preference information and would be limited to making inferences from simple demographic information. The MNL model was thus challenged to predict membership in these segments based solely on such demographics, which was a severe handicap to accuracy. The bottom of Table 3 shows the percentage of respondents belonging to each segment that were correctly predicted to be members of that segment. For the shelf-life segment, the MNL model correctly predicted $44 \%$, or 27 out of the 61 actual members.

The convenience segment, representing $17 \%$ of the sample, was so characterized because the preference coefficient on the peeled-and-sectioned product in Table 1 was large and positive (1.55), and package type contributed strongly $(42 \%)$ in relative importance. If other influences were held constant, $74 \%$ of the respondents in this segment would have chosen the convenience product as their first choice, and the remaining $26 \%$ would have chosen loose fruit as their first choice (Table 2 ). No one in this segment would have chosen bagged or boxed fruit first.

Although we identified the attributes and levels that influence the convenience segment's preferences - they like peeled-and-sectioned or loose tangerines with lower prices and longer shelf lives - the only demographic information in Table 1 that was found to be strongly associated with this segment was that they are more likely than the total sample to buy their citrus fruit in grocery stores $(94 \% \mathrm{vs}$. $82 \%$ in the total sample). Moreover, while the multinomial logit model in Table 3 correctly predicted $43 \%$ of the members of this segment based on demographic and usage information

Table 3. Marginal probabilities by consumer segment with respect to the vector of demographic variables (computed at the means)."

\begin{tabular}{|c|c|c|c|c|c|c|c|c|c|c|c|c|}
\hline \multirow[b]{3}{*}{ Variable } & \multicolumn{12}{|c|}{ Marginal probabilities of membership in each segment } \\
\hline & \multicolumn{2}{|c|}{$\begin{array}{c}\text { Prob[Segment= } \\
\text { "Shelf-life"] }\end{array}$} & \multicolumn{2}{|c|}{$\begin{array}{l}\text { Prob[Segment= } \\
\text { "Convenience"] }\end{array}$} & \multicolumn{2}{|c|}{$\begin{array}{l}\text { Prob[Segment= } \\
\text { "No-handling"] }\end{array}$} & \multicolumn{2}{|c|}{$\begin{array}{l}\text { Prob[Segment= } \\
\text { "Price-sensitive"] }\end{array}$} & \multicolumn{2}{|c|}{$\begin{array}{c}\text { Prob[Segment= } \\
\text { "Loose-fruit"] }\end{array}$} & \multicolumn{2}{|c|}{$\begin{array}{l}\text { Prob[Segment= } \\
\text { "Fuzzy-prefs"] }\end{array}$} \\
\hline & Coeff. & $p$ & Coeff. & $p$ & Coeff. & $\vec{p}$ & Coeff. & $p$ & Coeff. & $p$ & Coeff. & $p$ \\
\hline Intercept & $=0.1255$ & 0.60 & $=0.1612$ & 0.58 & 0.0140 & 0.90 & $=0.3000$ & 0.36 & $=0.0002$ & 1.00 & 0.5730 & 0.05 \\
\hline Store 4 & -0.1250 & 0.32 & 0.0100 & 0.90 & 0.0244 & 0.76 & 0.0351 & 0.68 & -0.0244 & 0.79 & 0.0799 & 0.49 \\
\hline Store 1 & -0.0299 & 0.73 & 0.0730 & 0.54 & 0.0602 & 0.32 & 0.0292 & 0.72 & -0.0975 & 0.38 & -0.0350 & 0.78 \\
\hline Store 3 & 0.0128 & 0.84 & 0.0304 & 0.66 & 0.0975 & 0.23 & 0.0167 & 0.81 & -0.1015 & 0.27 & -0.0560 & 0.58 \\
\hline Store 6 & 0.0756 & 0.42 & -0.0284 & 0.75 & -0.0270 & 0.74 & 0.1549 & 0.20 & -0.0836 & 0.44 & -0.0915 & 0.47 \\
\hline Store 5 & 0.0766 & 0.63 & -0.1375 & 0.53 & 0.0543 & 0.52 & 0.1732 & 0.29 & 0.0430 & 0.72 & -0.2095 & 0.23 \\
\hline Store 7 & 0.2019 & 0.35 & -0.9235 & 0.77 & 0.0701 & 0.47 & 0.2547 & 0.21 & 0.2363 & 0.18 & 0.1605 & 0.63 \\
\hline Sweet citrus allergic ( $\%$ yes) & 0.0942 & 0.38 & 0.0122 & 0.89 & 0.0966 & 0.24 & -0.0058 & 0.95 & -0.1338 & 0.43 & -0.0635 & 0.70 \\
\hline Sweet citrus bought $(\mathrm{kg} / \mathrm{mo}$.) & 0.0063 & 0.54 & -0.0079 & 0.55 & 0.0043 & 0.50 & 0.0036 & 0.68 & -0.0231 & 0.09 & 0.0168 & 0.30 \\
\hline Buy at grocery store ( $\%$ yes) & -0.0531 & 0.52 & 0.1652 & 0.50 & -0.1064 & 0.24 & 0.0399 & 0.59 & -0.0894 & 0.30 & 0.0437 & 0.70 \\
\hline Buy for Christmas (\% yes) & 0.1223 & 0.14 & -0.0199 & 0.71 & 0.0363 & 0.37 & 0.0355 & 0.48 & -0.0520 & 0.38 & -0.1221 & 0.17 \\
\hline Age (years) & -0.0043 & 0.00 & -0.0007 & 0.71 & -0.0020 & 0.34 & 0.0027 & 0.30 & 0.0024 & 0.29 & 0.0019 & 0.49 \\
\hline Gender ( $\%$ female) & 0.0125 & 0.83 & 0.0653 & 0.53 & -0.0317 & 0.48 & 0.0194 & 0.72 & 0.0491 & 0.48 & -0.1145 & 0.24 \\
\hline Ethnicity (\% Caucasian) & 0.2529 & 0.12 & -0.0528 & 0.59 & -0.0110 & 0.81 & 0.0576 & 0.49 & -0.1121 & 0.25 & -0.1345 & 0.26 \\
\hline Education (years) & 0.0080 & 0.51 & 0.0064 & 0.62 & 0.0090 & 0.42 & -0.0034 & 0.74 & 0.0015 & 0.90 & -0.0214 & 0.19 \\
\hline Income category & 0.0051 & 0.76 & -0.0054 & 0.69 & -0.0123 & 0.18 & 0.0010 & 0.95 & 0.0123 & 0.49 & -0.0007 & 0.97 \\
\hline Household with child $<9$ yrs & -0.0040 & 0.95 & 0.0770 & 0.52 & 0.0197 & 0.62 & 0.0570 & 0.42 & -0.1226 & 0.23 & -0.0271 & 0.78 \\
\hline Household with child 9-18 yrs & -0.0089 & 0.87 & -0.0039 & 0.94 & 0.0087 & 0.80 & -0.0401 & 0.49 & 0.0304 & 0.62 & 0.0137 & 0.86 \\
\hline Single person household & 0.0603 & 0.42 & 0.0372 & 0.62 & -0.0203 & 0.66 & -0.0098 & 0.87 & -0.0244 & 0.72 & -0.0431 & 0.63 \\
\hline Heard of satsumas ( $\%$ yes) & -0.0397 & 0.63 & 0.0486 & 0.60 & 0.0856 & 0.20 & -0.0199 & 0.81 & -0.0256 & 0.78 & -0.0489 & 0.66 \\
\hline Tasted satsumas ( $\%$ yes) & -0.0285 & 0.73 & -0.0447 & 0.62 & -0.1343 & 0.20 & 0.0829 & 0.39 & 0.1159 & 0.27 & 0.0087 & 0.94 \\
\hline Percent correctly predicted & \multicolumn{2}{|c|}{$44 \%$} & \multicolumn{2}{|c|}{$43 \%$} & \multicolumn{2}{|c|}{$19 \%$} & \multicolumn{2}{|c|}{$28 \%$} & \multicolumn{2}{|c|}{$22 \%$} & \multicolumn{2}{|c|}{$48 \%$} \\
\hline
\end{tabular}

${ }^{2}$ Multinomial logit model likelihood ratio statistic significant at $p<0.001$ 
alone, there were no significant marginal probabilities (in the form of coefficients from Table 3 ) that were associated with this segment.

Members of the no-handling segment, though representing only a $9 \%$ market share, were notable for their extreme dislike of the peeled-and-sectioned product. Casual conversation with some respondents after they had completed their surveys suggested that they did not at all like the prospect of someone else peeling their fruit, and this was our motivation for naming it the no-handling segment. This dislike was exceptionally strong, as underscored not only by the very large negative preference coefficient $(-2.67$; the largest in Table 1) but also by the relative importance value of $57.9 \%$ on package type (by far the highest relative importance of any attribute by any segment in Table 1). The adjusted $R^{2}$ of 0.75 was also the highest of any segment, indicating that the models of these consumers had more explanatory power than those of other segments. From Table 2 it is apparent that loose fruit and fruit in bags would be their preferred choice of package type ( $46 \%$ and $42 \%$ respectively), with boxed fruit a distant third. Not a single member of the no-handling segment would have chosen the peeled-and-sectioned form first.

Several demographic factors at the bottom of Table 1 differentiated the no-handling segment from the total sample: members of this segment gave significantly more affirmative answers to the "allergic to sweet citrus" question ( $15 \%$ vs. $6 \%)$, bought less citrus at grocery stores $(61 \%$ vs. $82 \%)$, and were of a younger average age (39.7 vs. 45.9$)$. In Table 3 , five variables were found to have a significant influence on the marginal probabilities, including: sweet citrus allergic, buy at grocery store, income category, heard of satsumas, and tasted satsumas. The consumer profile that emerges for the no-handling segment is that of a lower-income respondent who prefers to purchase sweet citrus from somewhere other than a grocery store (e.g., roadside stand, farmers market, etc.), is more likely to be allergic to citrus (though may be purchasing for others), and is more likely to have heard of satsumas, but less likely to have tasted them. Despite the number of significant coefficients found in Table 3, the model as a whole was not very good at predicting membership in the segment: only $19 \%$ of the members actually in this segment were correctly identified by the MNL model; the other $81 \%$ were predicted to be in other segments.

The fourth segment made up $14 \%$ of the sample and was subjectively labeled the pricesensitive segment because in Table 1 a large positive coefficient (1.76) was associated with the $\$ 2.18 / \mathrm{kg}$ price, a large negative coefficient $(-2.00)$ was associated with the $\$ 15.41 / \mathrm{kg}$ price, and $46 \%$ of their buying intention was related to the price attribute. Moreover, $98 \%$ of the members of this segment chose the lowest price as their first choice (Table 2).

In the bottom half of Table 1, the pricesensitive segment was characterized only by higher age, averaging six years more than the total sample (52 vs. 46 years). Though just meeting our liberal criterion for statistical significance in Table 3, the practical effect of age in the MNL model was small: if the mean age of the total sample were to increase by one year, then the probability of membership in this segment would increase by only $0.27 \%$. Prediction accuracy was only $28 \%$.

The loose-fruit segment made up 14\% of the sample and was characterized in Table 1 by its heavy weighting of relative importance on package type (40\%), with a very large positive coefficient (1.62) for the loose fruit form. Furthermore, in Table 2, 95\% of the segment specified loose fruit as their first choice in package type.

Although there were no demographic variables in the lower half of Table 1 that showed significant differences between this segment and the total sample, five of the marginal probabilities in Table 3 met our criterion for significance: amount of sweet citrus purchased per month, age, ethnicity, households with at least one person under nine years of age, and having tasted a satsuma. Of these variables, only age and having tasted a satsuma increased the likelihood of being in the segment. Thus, for the loose-fruit segment, the profile that emerges is one of older, non-Caucasian, less-frequent citrus buyers who are less likely to have a small child and more likely to have tasted satsumas (and not liked them). Membership in the segment was correctly predicted by demographics in the MNL model only $22 \%$ of the time.

The last segment, dubbed the fuzzy preferences segment because of the lack of any clear, distinguishing preferences, distributed most of their relative importance in Table 1 about equally among three of the five attributes. This lack of a singular preference for any particular attribute seemed to make this segment a residual category for respondents that could not be assigned definitively to one of the other clusters. The average explanatory power of their individual models (adjusted $R^{2}$ $=0.40$ ) was the lowest of all segments, and they showed no intense likes or dislikes among attributes, levels, or first choices.

Even though this segment did not show a preference for any particular attribute or level, it is still important to identify which consumers have these fuzzy preferences, especially since they represent nearly a quarter of the market share. Although the considerable variability within this segment obscured any significant differences from the total sample in Table 1, five marginal probabilities were significant in Table 3, including: amount purchased per month, Christmas purchasing, gender, ethnicity and education. The profile is of less-educated, non-Caucasian males who buy a lot of sweet citrus but not particularly at Christmas. Predictive accuracy for membership in this segment was relatively high at $48 \%$, compared to the average accuracy of $34 \%$ across the other five segments.

\section{Table 4. Simulating the market impact of peeled-and-sectioned satsumas: effect of price changes on market}

share and gross revenue

\begin{tabular}{|c|c|c|c|c|c|c|c|c|c|}
\hline \multirow[b]{2}{*}{ Mandarin } & \multirow{2}{*}{$\begin{array}{c}\text { Package } \\
\text { type }\end{array}$} & \multirow{2}{*}{$\begin{array}{c}\text { Shelf } \\
\text { life (days) }\end{array}$} & \multirow{2}{*}{$\begin{array}{c}\text { Vitamin C } \\
\text { label }\end{array}$} & \multirow{2}{*}{$\begin{array}{l}\text { Price } \\
\text { per kg }\end{array}$} & \multicolumn{5}{|c|}{ Price of peeled-and-sectioned satsumas ( $\mathrm{S} / \mathrm{kg}$ ) } \\
\hline & & & & & base $^{a}$ & $\$ 2.18$ & $\$ 6.59$ & $\$ 11.00$ & $\$ 15.41$ \\
\hline & & & & & \multicolumn{5}{|c|}{ Market share (\%) } \\
\hline Tangerine & Loose & 14 & no & $\$ 2.18$ & 33.0 & 27.4 & 28.8 & 29.7 & 30.2 \\
\hline Tangerine & Bag & 14 & no & $\$ 1.96$ & 21.1 & 17.7 & 18.6 & 19.1 & 19.4 \\
\hline Clementine & Box & 14 & no & $\$ 2.18$ & 19.5 & 16.1 & 16.8 & 17.1 & 17.3 \\
\hline Satsuma & Loose & 14 & no & $\$ 2.18$ & 26.4 & 21.3 & 22.4 & 23.2 & 23.6 \\
\hline Satsuma & Peel-\&-sec & 3 & yes & Svariable & & 17.6 & 13.5 & 10.9 & 9.4 \\
\hline
\end{tabular}

\begin{tabular}{|c|c|c|c|c|c|c|c|c|c|}
\hline \multirow[b]{2}{*}{ Tangerine } & \multirow[b]{2}{*}{ Loose } & \multirow[b]{2}{*}{14} & \multirow[b]{2}{*}{ no } & \multirow[b]{2}{*}{$\$ 2.18$} & \multicolumn{5}{|c|}{ Gross revenue index (unitless) } \\
\hline & & & & & 72.0 & 59.7 & 62.8 & 64.8 & 65.9 \\
\hline Tangerine & Bag & 14 & no & $\$ 1.96$ & 41.4 & 34.7 & 36.4 & 37.5 & 38.0 \\
\hline Clementine & Box & 14 & no & $\$ 2.18$ & 42.6 & 35.0 & 36.5 & 37.4 & 37.8 \\
\hline Satsuma & Loose & 14 & no & $\$ 2.18$ & 57.4 & 46.3 & 48.8 & 50.5 & 51.5 \\
\hline Satsuma & Peel-\&-sec. & 3 & yes & Svariable & 0.0 & 38.3 & 88.6 & 119.8 & 145.3 \\
\hline \multicolumn{3}{|c|}{ Sum of two satsuma products } & & & 57.4 & 84.7 & 137.4 & 170.3 & 196.8 \\
\hline
\end{tabular}

${ }^{a}$ Baseline market share and gross revenue before introduction of new product 
As mentioned in the introduction, an important objective of this study was to assess the acceptability of a peeled-and-sectioned product in grocery stores. To this end, we conducted a simulation of the introduction of a new satsuma product in this form into an existing mix of other mandarin products commonly found in grocery stores (incumbents). Four mandarin products were simulated as incumbents: loose tangerines at $\$ 2.18 / \mathrm{kg}$, bagged tangerines at $\$ 1.96 / \mathrm{kg}$, boxed clementines at $\$ 2.18 / \mathrm{kg}$, and loose satsumas at $\$ 2.18 / \mathrm{kg}$. All these products were simulated as having 14-d shelf lives, and no labeling relating to vitamin $\mathrm{C}$. The tangerine prices represented premium prices for seedless, fancy and organic tangerine varieties such as Dancy, Sunburst and Fairchild. Clementine prices were similar to those commonly noted in the study region for $2.27-\mathrm{kg}$ boxes imported from Spain and South Africa. Prices for loose satsumas were set equal to their premium tangerine and clementine competitors. Lacking its protective peel, the hypothetical form of the satsuma was assumed to have a very short (3-d) shelf life due to rapid dehydration of the skin surrounding the sections. Since they were displayed in the photograph in a clear plastic clamshell, we decided to take advantage of the space available on the packaging and assume it could support a label promoting the benefits of vitamin $\mathrm{C}$, whereas the incumbents were assumed to lack this label.

The price of the value-added satsuma was simulated at four selected points over the range of prices tested in the study $(\$ 2.18$ to $\$ 15.41 / \mathrm{kg}$ ) and the market shares were calculated using a first-choice model (Nelson et al., 2005). This method inserted the simulated values of the variables into each respondent's preference model, generated the predicted intention-tobuy rating for each of the five products by each respondent, counted the highest rating as the first (and only) choice for purchase, and calculated the percentage of first choices for each product as representative of the simulated market share. A gross revenue index was then calculated by multiplying the market share for each product by its simulated price. Gross revenue is only a relative or index value, rather than a dollar figure, because we do not know the number of units of product sold, only their relative share of the market.

Table 4 shows the simulated impact of the new product on market shares and gross revenues. The first five columns represent product attributes, and the rows indicate which attribute level is present in each product. The upper right half of the table shows the percentage market share predicted when the price of the new product is allowed to change while all other levels of the five products remain the same. The lower right half shows the revenue consequences of those predicted market share changes, which are calculated by multiplying price by market share. The last row is simply the sum of the two rows above it, and represents the revenue impact for satsuma producers of their combined products. This is useful in evaluating the extent to which one satsuma product cannibalizes the other.

Before introduction of the new product, the base market share of satsumas was $26.4 \%$ and the gross revenue index (GRI) was 57.4. After introduction of the new product at the same price as three of the other products, the combined market share of satsumas (i.e. loose at $21.3 \%$, plus peeled-and-sectioned at $17.6 \%$ ) jumped to $38.9 \%$ and the GRI to 84.7 . Continued price increases up to $\$ 15.41 / \mathrm{kg}$ (the highest price used in our study), while predictably decreasing market shares of the new product, nevertheless steadily pushed the combined-satsuma GRI up to 196.8 , a $243 \%$ increase above the value of satsumas without the new package type. This gives some indication of how high prices of peeledand-sectioned satsumas could be set without negatively impacting revenues for satsumas as a whole. In summary, although the cost of producing this form is not known at this time, the potential for this product seems to warrant further consideration, particularly since it can be produced from cull fruit whose internal quality is fine, but whose external (unpeeled) appearance would not meet the market's fastidious standards for whole fruit.

\section{Implications and Conclusions}

This study contributes to a larger marketing effort that is following the classical sequence of the marketing process: analyzing marketing opportunities (including researching and identifying market segments), selecting target markets, developing the marketing mix (including products, pricing, distribution, and promotion), and managing the marketing effort (Kotler and Armstrong, 2004, p. 53). While results from this study contribute to all of these steps, the emphasis is on the first step.

In analyzing marketing opportunities, we specifically examined those that involve package form, shelflife, mandarin name, vitamin C label, and price. A package form of particular interest was peeled-and-sectioned fruit in a clamshell container. Opportunities for providing products with longer shelf lives, and simple labeling directing attention to vitamin $\mathrm{C}$ content were also of special interest. But, in order for analysis of these opportunities to have an objective, scientific foundation, it is first necessary to quantify the tradeoffs between the potential benefits of these opportunities and their potential costs.

In researching and identifying market segments, our first objective was to evaluate consumer preferences for the selected attributes among a sample of grocery store consumers in our study region. This information was used to construct individual models of 289 respondents' preferences for a range of levels of the selected attributes. Those models now serve as a foundation from which to begin evaluations of how the general consumer population (at least as represented by the sample) might assess the cost-benefit tradeoffs of these opportunities. One of the less surprising implications of this initial evaluation was that, disregarding price, the highest rated product for the full sample was the loose tangerine with a 31-d shelf life and a vitamin $\mathrm{C}$ label. However, an objective of the study was also to uncover segments of consumers-representing subsets of the full sample - that might have very different preferences. In examining the six most highly differentiated segments, it became apparent that trying to satisfy the preferences of all those segments with the same product profile is simplistic - some consumers want the lowest price, while others want a longer shelf life or a ready-to-eat product and are willing to pay more for these features.

One of the segments we identified, representing $17 \%$ of the sample, rated the peeledand-sectioned product highly in their intention-to-buy responses. However, this segment was somewhat sensitive to higher prices, so it was not apparent from the preference evaluation alone whether the benefits of providing this form outweighed the costs, i.e., whether these consumers valued the new product form enough to cover its cost of production. So we probed further into the data using a simulation of the relative changes in gross revenues that followed from changes in the price of the peeled-and-sectioned form. While the simulation showed substantial increases in gross revenues up to the highest price used in the study $(\$ 15.41 / \mathrm{kg})$, it is important to note that the tradeoffs in the special context of this simulation refer only to reductions in sales or market share (costs) that follow from increases in prices (benefits). The actual costs of processing and packaging - including the peeling and sectioning of mandarins either by hand or machine - also need to be taken into account. Consequently, given the favorable implications of the market simulation, these variables are currently being assessed as a part of the continuing marketing process.

The segmentation results also have implications for the product mix in a retail setting: while members of one segment strongly preferred the peeled-and-sectioned product, members of two other segments (no-handling and loose fruit) strongly disliked that particular product form, and they represented a combined market share of $37 \%$. Thus, we recommend that in any marketplace where these three segments are all likely to be shopping, it is imperative to provide a mix of product forms, or at least loose fruit along with the peeled-and-sectioned product, so as not to preclude sales to certain segments entirely.

Another segment identified in our study rated the vitamin $\mathrm{C}$ label $>70 \%$ higher than any other segment. But they also preferred loose fruit, a package that does not provide much space for a label, so other labeling graphics would be required. This segment also preferred to buy their mandarins from sources other than grocery stores, suggesting that roadside stands and farmers markets should be encouraged to advertise the high-in-vitamin-C attribute of their mandarins.

An implication from this study that should be of concern to the satsuma industry is that, while tangerines and clementines are well perceived, satsumas are a distant third in terms of preferred type or name of mandarin (only 19\% of consumers made them their first choice). In fact, the base intention-to-buy rating for the full sample was lowered by $5 \%$ (or 0.20 
rating points) when the name satsuma was on the photograph of the generic mandarin, compared to a $3 \%$ increase in the rating when the name was tangerine and a $2 \%$ increase for clementine. This is likely the result of low awareness and name recognition, rather than a dislike for the taste or quality of satsumas, but nonetheless indicates a pressing need for promotional campaigns to raise awareness and recognition among consumers unfamiliar with this mandarin.

In addressing the second step in the marketing process - selecting target markets - a few implications can be made from the results presented here, but in most segments the relationships between demographics and preferences were tenuous at best. For example, the segment that strongly preferred the longest shelf life appeared to make purchases in connection with the Christmas holidays, suggesting that this segment might value the application of wax or fungicides to give the fruit a decorative sheen and inhibit shriveling due to dehydration. A follow-up conjoint survey would be needed to evaluate wax and fungicides as additional attributes with potential for product differentiation. Also, further research is in progress to implement other segmentation schemes that do not necessarily create mutually exclusive sets of consumers with maximal differences in preferences. For instance, it may prove useful to construct the demographic profiles of the consumers who strongly prefer boxed clementines, or low-priced bagged tangerines.

Results from this survey are currently being communicated to mandarin growers, processors and distributors to encourage them to provide products that add variety and value for consumers, and thereby compete well with other fruits in the marketplace. Case-specific applications and extensions of these results are underway to complete the steps in the marketing process by helping producers develop the marketing mix and manage marketing efforts.

\section{Literature Cited}

Behe, B., R. Nelson, S. Barton, C. Hall, C.D. Safley, and S. Turner. 1999. Consumer preferences for geranium flower color, leaf variegation, and price. HortScience 34(4):740-742.

Behe, B.K., R.M. Walden, M.W. Duck, B.M. Cregg, K.M. Kelley, and R.D. Lineberger. 2005. Consumer preferences for tabletop Christmas trees. HortScience 40(2):409-412.

Campbell, B.L., R.G. Nelson, R.C. Ebel, W.A. Dozier, J.L. Adrian, and B. Hockema. 2004. Fruit quality characteristics that affect consumer preferences for satsuma mandarins. HortScience 39(7):1664-1669.
Frank, C.A., R.G. Nelson, E.H. Simonne, B.K. Behe, and A.H. Simonne. 2001. Consumer preferences for color, price, and vitamin C content of bell peppers. HortScience 36(4):795-800.

Green P.E. and K. Helsen. 1989. Cross-validation assessment of alternatives to individual-level conjoint analysis: A case study. J. Mktg. Res. 26:346-350.

Green, P.E., A.M. Krieger, and Y. Wind. 2001. Thirty years of conjoint analysis: reflections and prospects. Interfaces 31(3):S56-S73.

Hair, Jr., J.F., R.E. Anderson, R.L. Tatham, and W.C. Black. 1998. Multivariate analysis. 5th ed. Prentice Hall, Upper Saddle River, N.J.

Kelley, K.M., B.K. Behe, J.A. Biernbaum, and K.L. Poff. 2002. Combinations of colors and species of containerized edible flowers: effect on consumer preferences. HortScience 37(1):218-221.

Kotler, P. and G. Armstrong. 2004. Principles of marketing. 10th ed. Pearson Education, Inc. Upper Saddle River, N.J.

Liao, T.F. 1994. Interpreting probability models: logit, probit, and other generalized linear models. Sage university paper series on quantitative applications in the social sciences, series no. 07-101, Thousand Oaks, Calif.

Nelson, R.G., C.M. Jolly, M.J. Hinds, Y. Donis, and E. Prophete. 2005. Conjoint analysis of consumer preferences for roasted peanut products in Haiti. Intl. J. Consumer Studies 29(3):208-215.

SAS Institute Inc. 1987. SAS user's guide: Statistics, 5th ed. SAS Institute Inc., Cary, N.C. 